\title{
Sacral Orientation in Hominin Evolution
}

\author{
Ella Been ${ }^{1,3^{*}}$, Hayuta Pessah ${ }^{2}$, Smadar Peleg ${ }^{3}$, Patricia A. Kramer ${ }^{4}$ \\ ${ }^{1}$ Department of Anatomy and Anthropology, Sackler Faculty of Medicine, Tel Aviv University, Tel Aviv, Israel \\ ${ }^{2}$ Department of Anatomy, Zinman College, Wingate Institute, Netanya, Israel \\ ${ }^{3}$ Physical Therapy Department, Zefat Academic College, Zefat, Israel \\ ${ }^{4}$ Departments of Anthropology and Orthopaedics, University of Washington, Seattle, USA \\ Email: "beenella@post.tau.ac.il
}

Received February $15^{\text {th }}, 2013$; revised March $21^{\text {st }}, 2013$; accepted March $27^{\text {th }}, 2013$

Copyright (C) 2013 Ella Been et al. This is an open access article distributed under the Creative Commons Attribution License, which permits unrestricted use, distribution, and reproduction in any medium, provided the original work is properly cited.

\begin{abstract}
Sagittal sacral orientation within the pelvic girdle of humans is a key component of posture and obstetrics. On the one hand, sacral orientation has direct influence on the lumbar curvature; while on the other hand, it has an impact on the dorsoventral dimension of the birth canal. In this study, we aim to explore the evolution of sacral orientation in the sagittal plane and its relationship with the lumbar curvature in hominins. To do this, we measured sacral orientation using the pelvic incidence (PI) angle of the pelves of 53 modern humans, 19 nonhuman hominoids, and 4 fossil hominins. Our results show that the PIs of modern and fossil $H$. sapiens are the highest while the PI of nonhuman hominoids is the lowest (a nearly parallel sacrum in relation to the hip bone). Australopithecines PI is higher than that of nonhuman hominoids, but lower than that of modern humans. The PI of Homo heidelbergensis and H. neanderthalensis (Neandertal lineage hominins) is the lowest among hominins. We also found a strong correlation between lumbar lordosis and PI in nonhuman hominoids and hominins, indicating that PI angle is a good predictor of the lumbar lordosis when only the pelvis is preserved. We conclude that sacral orientation changed during the course of human evolution. When Neandertal lineage hominins are ignored, the results indicate a fairly simple path of evolution from nonhuman hominoid-like to human-like sacral orientation with two stages of the development. Neandertal lineage hominins show a reversal of this trend.
\end{abstract}

Keywords: Posture; Bipedal Gait; Obstetric; Australopithecus; Neandertal; H. sapiens

\section{Introduction}

Pelvic morphology plays a paramount role in posture and locomotion, and the orientation of the sacrum in the pelvic girdle is a critical aspect of pelvic morphology. The sacrum supports the upper body in standing and walking by transferring weight from the spine to the pelvis and the lower limb (Lazennec et al., 2004; Peleg et al., 2007) and, therefore, the size, position, and orientation of the sacrum dictate much of the vertebral column's form, shape and stability (Peleg et al., 2007).

During the evolution of bipedal gait in hominins, sacral orientation underwent distinct changes. In contrast to the tall and narrow pelvis of Miocene apes (Ward, 1993; Lovejoy, 2005; Crompton et al., 2008), the shallow and broad pelvis of hominins exhibits a sacrum that is closer to the acetabulum and enhances stability (Tague \& Lovejoy, 1986; Crompton et al., 2008). At the same time, the sacrum moved from a position that is almost parallel to the iliac blades when viewed from the side to the distinctive angled sacrum of humans. This relationship of the sacrum to the iliac blades is called sacral tilt and the human sacrum is described as "tilted" (Hogervorst et al., 2009). In erect posture (anatomical position), when the anterior superior iliac spines and the pubic symphysis are situated in the same vertical plane, a strong tilt means more horizontal sacrum (Hogervorst et al., 2009), and a small tilt means a more vertical

${ }^{*}$ Corresponding author. sacrum (Figure 1). The tilting of the sacrum in the pelvis is concordant with the development of lordotic curvature (lumbar lordosis), which aligns the spine in erect posture: more vertical i.e., less tilted sacra are related to less lordotic lumbar spines while tilted sacra are related to more lordotic lumbar spines. (Tardieu et al., 2006; Boulay et al., 2006; Legaye, 2007). Some authors have proposed explanations for the change in sacral tilt in bipedal hominins (Abitbol, 1987; Lovejoy, 2005; Hogervorst et al., 2009): the obstetric hypothesis, which suggests that the sacrum is tilted in order to accommodate the pelvic outlet to the enlarged fetal head of humans; and the locomotive hypothesis, which correlates sacral tilt to the biomechanical demands of erect posture and bipedalism, as it serves to bring the weight of the trunk closer to the acetabulum (Abitbol, 1987).

Sacral curvature and sacral length also influence the dorsoventral dimension of the birth canal. A more curved sacrum brings the tip of the sacrum closer to the pubis and, therefore, reduces the dorsoventral dimension of the pelvic outlet. A longer (cranio-caudal) sacrum also reduces the dorsoventral dimension of the pelvic outlet (Tague, 2000). Although both sacral curvature and length are important aspects determining the dimensions of the bony birth canal, our focus in this report is on the orientation of the sacrum within the pelvis.

Paleoanthropologists have used different methods to describe the orientation of the sacrum in hominins and the use of these 
different methods and reconstructions has led to opposing views regarding sacral tilt. For example, Abitbol (1995a, 1995b) reports a horizontal sacrum in an anatomical position in AL288-1 and in STS-14, while Berge \& Goularas (2010) report a more vertically oriented sacrum in the same specimens. The clinical literature supplies an abundance of measurement methods for sacral orientation (Von Lackum, 1924; Ferguson, 1934; Stagnara et al., 1982; During et al., 1985; Duval-Beaupère et al., 1992; Jackson \& McManus, 1994; Gardocki et al., 2002; Labelle et al., 2005), but, unfortunately, most of these methods are only applicable to living individuals and are not useful in osteological remains because they are positional dependent. One method for assessing sacral orientation that is an exception to this requirement for living representatives is pelvic incidence (PI) angle. PI is a measure of the relationship between a line connecting the acetabula and the sacral endplate (Tardieu et al., 2006). Although several morphological features influence PI, it is, in essence, a measure of the inclination of the first sacral vertebra (S1) endplate to the axis of rotation of the body on the hind limbs. Variability in PI angle indicates differences in the spatial relationship between the sacral endplate and the acetabula and, consequently, PI has functional importance (Figure 1) (Duval-Beaupère et al., 1992; Legaye et al., 1998). PI is considered posture independent and can be easily measured on osteological material using radiographs or 3-D landmark analysis (Legaye et al., 1998; Labelle et al., 2005; Peleg et al., 2007). For an individual, the value of PI does not change with pelvic orientation. It is, therefore, not necessary to know the habitual posture (orientation of the pelvis to the femur) of the individual in order to calculate PI.

The PI of modern humans is often described in terms of the anatomical planes. When the pelvis of humans is held in anatomical position, greater PI indicates increased sacral inclination (the angle between the posterior wall of the first sacral vertebra and the vertical line) meaning a more horizontal sacrum (greater sacral tilt). Greater PI also indicates more vertical sacral endplate (greater sacral slope) and increased lumbar lordotic curvature (Legaye, 1998; Boulay et al., 2006; Peleg et al., 2007). Smaller PIs indicates decreased sacral inclination meaning a more vertical sacrum (smaller sacral tilt), horizontal sacral endplate (small sacral slope), and decreased lordotic curvature (Tardieu et al., 2006; Legaye, 2007) (See Figure 1). Boulay et al. (2006) and Legaye (2007) found strong and positive correlations between all of the above variables (PI, sacral inclination, sacral slope, lumbar lordosis) indicating that PI is a good measurement to describe sacral orientation. Specifically Legaye (2007) showed that PI correlates with the orientation of the posterior wall of the sacrum in relation to the horizontal plane and in a relation to the femoral heads. For example, a person with a low PI $(<44)$ also has a decreased sacral-slope, a more vertical sacrum and the lordosis will be flattened. On the other hand, a person with a high PI $(>62)$ also has an increased sacral slope, a more horizontal sacrum, and the lordosis will be more pronounced (Boulay et al., 2006; Legaye, 2007).

If the human pelvis is rotated out of anatomical position, the description (e.g. "more vertical") will change, but the value of PI will not. Other values, such as sacral table angle, will also remain the same, as they are measured within the pelvis, and are not influenced by pelvic spatial orientation (Legaye, 2007). Therefore, although several morphological features influence PI, it is, in essence, a measure of the inclination of the S1 endplate to the axis of rotation of the body on the hind limbs. Variability

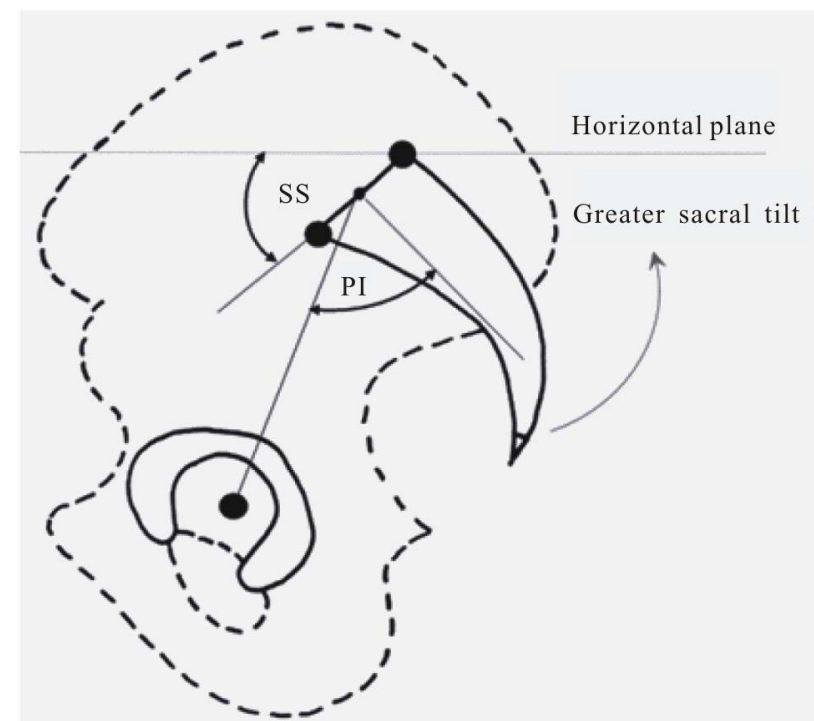

Figure 1.

Pelvic incidence (PI), sacral slope (SS) and an arrow describing the direction of increased sacral tilt in relation to the acetabular line.

in PI angle indicates differences in the spatial relationship between the sacral endplate and the acetabula and, consequently, PI has functional importance. PI is well established in modern humans; but it has not been thoroughly explored in nonhuman primates (NHP) or in fossil hominins. Only two studies have previously measured PI in fossil hominins and non human primates (Tardieu et al., 2006; Bonmatí et al., 2010) and their results were compared only with modern humans.

The goals of this study, therefore, are twofold: first, we establish the orientation of the sacrum relative to the acetabula (using PI as the metric) for nonhuman hominoids and for fossil hominins and compare those values to that of modern humans, in order to establish the change in sacral orientation during the course of human evolution; and second, as it has been shown that PI is a good indicator for lumbar lordosis in modern humans, we would like to explore the relationship between sacral orientation and lumbar lordosis in nonhuman hominoids and hominins. If indeed such correlation exists, it would enable us to predict the lordosis angles for fossil hominins that preserve only their pelvic bones.

\section{Materials and Methods}

\section{Materials}

The pelves of 19 extant nonhuman hominoids, 53 modern humans and four fossil hominin specimens were measured. In the modern human group, we measured 49 pelvic radiographs and four pelves. The nonhuman hominoid sample included eight chimpanzees (Pan troglodytes), three gorillas (Gorilla gorilla), three orangutans (Pongo pygmaeus), and five gibbons (Hylobates sp.). In this group, we measured 13 radiographs and 6 pelves (Table 1). The radiographs of the apes are part of the collection of Tel Aviv University, the veterinary hospital in Rishon Le Zion, and the Biblical Zoo in Jerusalem, Israel. The radiographs of the modern humans were used in a previous study (Been et al., 2007). The skeletal and cast material (modern human, nonhuman hominoids and fossil hominins) is housed in the osteological collection of Tel Aviv University. 
All of the pelves that were used in this study belonged to mature individuals without major pelvic pathology (e.g. no fractures, degeneration, etc).

The hominin sample included the pelves of: Australopithecus afarensis (AL-288-1); A.africanus (STS-14); H. neanderthalensis (Kebara 2); and fossil H. sapiens (the original of Ohalo) (See Table 2). We did not have access to the pelves from Gona (Simpson et al., 2008) or Au. sediba (Kibii et al., 2011). We also used the PI angles of two Homo heidelbergensis (Pelvis 1 and Pelvis 2 from Atapuerca, Sima de los Huesos) after Bonmatí et al., 2010. For the analyses described below, the two australopithecines were grouped based on shared pelvic features and a (presumed) close phylogenetic relationship. Likewise, the two specimens of $H$. heidelbergensis were grouped with the $H$. neanderthalensis specimen for similar reasons and are designated "Neandertal lineage" (See also Stringer, 2012).

We acknowledge that PI might be influenced by pathology or by post-mortem changes in pelvic morphology. This potential problem is relevant to pelvis 1 from Sima de los Huesos, which has changes in sacral endplate morphology probably due to spondylolisthesis of the last lumbar vertebra (Pérez, 2003; Bonmatí et al., 2010), and the sacrum of Kebara 2, which has a remarkably flat shape (Rak, 1991; Duday \& Arensburg 1991; Weaver, 2002; Bonmatí et al., 2010). The degree to which either pathology or post-mortem changes might influence the measured PI of these specimen is not known. The lumbar lordosis data was taken from our previous publications (Been et al., 2007, 2010, 2012).

Table 1.

Pelvic incidence of modern humans fossil hominins and nonhuman hominoids.

\begin{tabular}{ccc}
\hline & No. of pelves measured & PI \\
\hline Total/radiographs/digital & Xd, (range) \\
\hline Nonhuman hominoids (total) & $19 / 13 / 6$ & $27 \pm 5(20-38)$ \\
Pan & $8 / 3 / 5$ & $29 \pm 6$ \\
Gorilla & $3 / 3 / 0$ & $28 \pm 7$ \\
Pongo & $3 / 2 / 1$ & $28 \pm 6$ \\
Hylobates & $5 / 3 / 2$ & $25 \pm 4$ \\
Modern H. sapiens & $53 / 49 / 4$ & $54 \pm 10(32-84)$ \\
Fossil H. sapiens & $1 / 0 / 1$ Ohalo (original) & 52 \\
Neandertal lineage (combined group, the & $3 / 0 / 3$ & $32 \pm 3$ \\
and Kebara 2) & Kebara 2 (cast) & 34 \\
& Sima de los Huesos, pelvis 1* & 28 \\
Australopithecines & Sima de los Huesos, pelvis 2* & 33 \\
& $2 / 0 / 2$ & $43.5 \pm 2$ \\
\end{tabular}

*after Bonmatí et al. (2010).

Table 2.

Hominin specimens.

\begin{tabular}{|c|c|c|c|c|c|c|}
\hline Individual & Species & Chronology & Location & Observations & Reconstruction & State of preservation \\
\hline STS-14 & $\begin{array}{l}\text { Australopithecus } \\
\text { africanus }\end{array}$ & $\begin{array}{l}2.5 \mathrm{Ma} \\
\text { (Schwarcz et } \\
\text { al., 1994) }\end{array}$ & $\begin{array}{l}\text { Sterkfontein, } \\
\text { South Africa }\end{array}$ & $\begin{array}{c}\text { Young adult } \\
\text { Robinson (1972), } \\
\text { (Bonmatí et al., 2008). }\end{array}$ & $\begin{array}{l}\text { Robinson } \\
\text { (1972). }\end{array}$ & $\begin{array}{l}\text { Robinson (1972) described } \\
\text { the fossil as a "virtually } \\
\text { complete pelvis" that "has } \\
\text { suffered relatively little } \\
\text { damage." Two sacral } \\
\text { vertebrae are intact S1-S2. }\end{array}$ \\
\hline AL-288-1 & $\begin{array}{l}\text { Australopithecus } \\
\text { afarensis }\end{array}$ & $\begin{array}{c}3.2 \mathrm{Ma} \\
\text { (Walter, 1994) }\end{array}$ & $\begin{array}{l}\text { Hadar, } \\
\text { Ethiopia }\end{array}$ & Adult female. & $\begin{array}{l}\text { Lovejoy } \\
\text { (1979). }\end{array}$ & $\begin{array}{l}\text { Nearly complete sacrum } \\
\text { and left innominate. Five } \\
\text { sacral vertebrae. }\end{array}$ \\
\hline Kebara 2 & H. neanderthalensis & $\begin{array}{c}60 \mathrm{Ka} \\
\text { (Valladas et al., } \\
\text { 1987) }\end{array}$ & Israel & $\begin{array}{c}20 \text { - } 30 \text { years old male } \\
\text { (Arensburg et al., } \\
\text { 1985) }\end{array}$ & $\begin{array}{l}\text { Rak } \\
\text { (1991). }\end{array}$ & $\begin{array}{l}\text { Complete pelvis. Five } \\
\text { sacral vertebrae }\end{array}$ \\
\hline $\begin{array}{l}\text { Sima de los } \\
\text { Huesos } \\
\text { Pelvis } 1\end{array}$ & H. heidelbergensis & $\begin{array}{c}0.6 \mathrm{Ma} \\
\text { (Bischoff et al., } \\
\text { 2007) }\end{array}$ & Spain & $\begin{array}{l}\text { Over } 45 \text { years } \\
\text { old male. }\end{array}$ & $\begin{array}{l}\text { Bonmatí et al., } \\
\text { (2010). }\end{array}$ & $\begin{array}{l}\text { Nearly complete pelvis. Six } \\
\text { sacral vertebrae. } \\
\text { Asymmetry between the } \\
\text { morphology of the right } \\
\text { and left auricular surfaces. }\end{array}$ \\
\hline $\begin{array}{c}\text { Sima de los } \\
\text { Huesos Pelvis } 2\end{array}$ & H. heidelbergensis & $\begin{array}{c}0.6 \mathrm{Ma} \\
\text { (Bischoff et al., } \\
\text { 2007) }\end{array}$ & Spain & & $\begin{array}{l}\text { Bonmatí et al., } \\
\text { (2010). }\end{array}$ & $\begin{array}{l}\text { Nearly complete left } \\
\text { os coxae and first sacral } \\
\text { vertebra }\end{array}$ \\
\hline Ohalo & H. sapiens & $\begin{array}{c}20 \mathrm{Ka} \\
\text { (Nadel and } \\
\text { Hershkovitz, } \\
\text { 1991) } \\
\end{array}$ & Israel & $\begin{array}{c}\text { Adult male } \\
\text { (Nadel and } \\
\text { Hershkovitz, 1991) }\end{array}$ & & $\begin{array}{l}\text { Complete os coxae and } \\
\text { sacrum. }\end{array}$ \\
\hline
\end{tabular}




\section{Methods}

Pelvic incidence (PI) is the angle between a line drawn perpendicular to the superior endplate of the first sacral vertebra (S1) at its midpoint (the center of the sagittal diameter) and the line connecting this point to an axis that connects the center of the acetabula (Legaye et al., 1998; Legaye \& Duval-Beaupère, 2008), as is demonstrated in Figures 1 and 2. This is a measure of the orientation of the $\mathrm{S} 1$ endplate to the axis of rotation of the body on the hind limbs.

In this study, PI was measured using either a radiological or a digital approach. In the radiological approach, PI was measured on plain lateral pelvic radiographs. The radiographs of humans were taken while the subjects were standing; the radiographs of the nonhuman hominoids were taken while the subjects were lying on their sides. Measurements were conducted as described below, following the instructions by Duval-Beaupère et al. (1992) and Legaye et al. (1998) (See Figure 2). The PI angle was measured using a $25 \mathrm{~cm}$ Jamar goniometer with a $360^{\circ}$ scale in $1^{\circ}$ increments. In the digital approach, four anatomical landmarks were used, including two on the superior endplate of the first sacral vertebra (at the ventral and dorsal edge of the vertebral endplate in the midsagittal plane) and two at the centers of the acetabula (Figure 1). The XYZ coordinates of each landmark was recorded using a 3D microscribe (Immersion, San Jose, California; accuracy of $\pm 0.3 \mathrm{~mm}$ ) and measured on an articulated pelvis. PI was calculated based on these 4 points as described by Peleg et al. (2007). All of the pelves that were measured digitally were articulated.

Each of the hominin pelves was measured twice and the results presented are the average of the measurements. Descriptive statistics, Mann-Whitney test including Dunn-Šidák correction for multiple comparisons $\left[1-(1-\alpha)^{1 / n}\right]$, and Pearson correlation analysis were performed using JMP8 (JMP statistics software, SAS institute, Cary, NC).

We examined the correlation between PI and lordotic angle in nonhuman hominoids and hominins. To perform the calculation, we used the PIs from this study and the lumbar lordotic

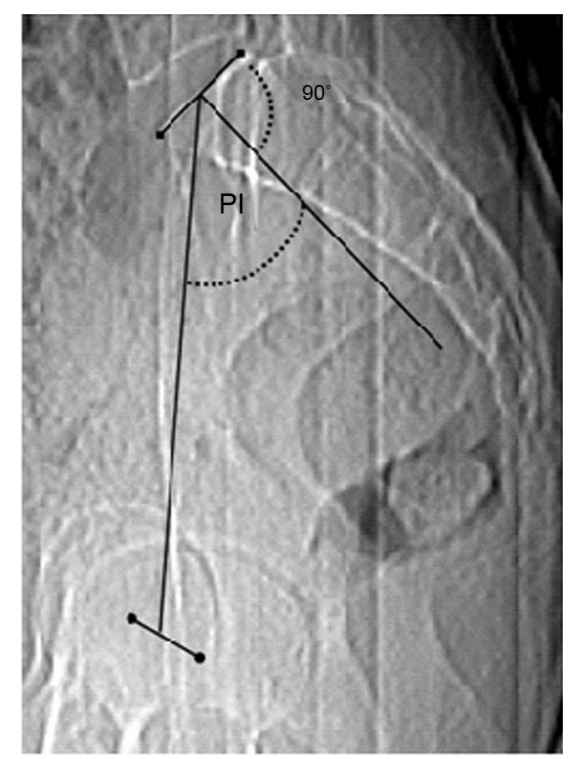

Figure 2.

Radiological measurement of pelvic incidence (PI) drawn on the pelvis of a modern human. angles from a previous study (Been et al., 2012). The lordosis angle of living individuals (humans and nonhuman hominoids) was measured on lateral spinal radiographs using the Cobb method. Measurement was taken between the superior endplate of the first sacral vertebra and the superior end plate of the fifth presacral vertebra which is the first lumbar vertebra in humans (for more details see Been et al., 2010) (Figure 3). Fossil hominin lordosis was calculated based on the relationship between the lordotic curvature and the orientation of the inferior articular processes in the lumbar spines of a combined group of living human and nonhuman primates (Been et al., 2010, 2012). Because the method uses a measurement taken within each vertebra, articulation of the entire lumbar spine is not required. This method explains $89 \%$ of the variation in lordotic curvature among living primates (Been et al., 2010, 2012).

The small number of fossil hominins in our sample lessens the power of the inferential statistical methods and we have had to rely mostly on descriptive analysis. Our hominin results should, therefore, be taken with caution. Future findings with new fossils might change the pattern we see.

Because there were no significant differences between the radiologic measurements and the $3 \mathrm{D}$ measurements, as has been shown previously (Boulay et al., 2005; Peleg et al., 2007), we present only the combined results from the radiographic and digital approaches (Tables 1 and 3, Figure 4).

The PI of the fossil H. sapiens Ohalo is similar to the PIs of modern humans (Table 4) both have significantly higher $(p<$ $0.01)$ PI than any other group. The PIs of each of the australopithecines are within the range of PI of modern humans and higher than the PI of nonhuman hominoids (Table 4). When we apply the Mann-Whitney test for the australopithecines as one group we find that their PI is significantly higher $(p<0.01)$ than the PIs of nonhuman hominoids, and significantly lower $(p$ $<0.01)$ than the PIs of modern humans.

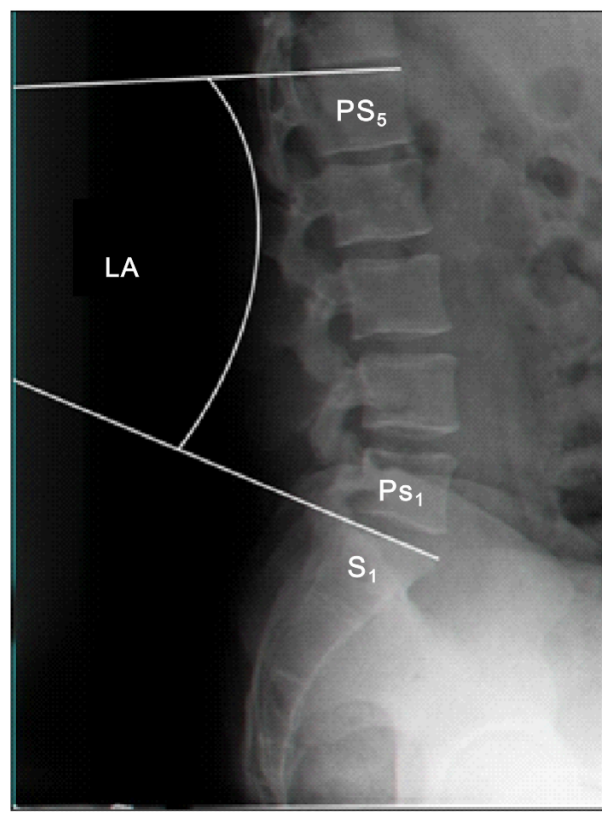

Figure 3.

Measurement of lordosis angle using the Cobb method on lateral spinal radiograph of the lumbar spine of a modern human. 
The PIs of each of the specimens from the Neandertal lineage are smaller than the PI of modern humans and within the range of PI of nonhuman hominoids. As a group the PIs of the Neandertal lineage hominins $\left(32^{\circ} \pm 3^{\circ}\right)$ are higher than that of nonhuman hominoids $\left(27^{\circ} \pm 5^{\circ}\right)$ although the difference does not reach statistical significance $(p=0.11)$, and significantly lower $(p<0.001)$ than the PIs of modern humans. The PIs of Neandertal lineage hominins are also smaller than that of australopithecines $(p=0.016)$.

When we apply the Dunn-Šidák correction for multiple comparisons $\left[1-(1-\alpha)^{1 / n}\right]$ with an $\alpha=0.05$ and four groups considered (modern humans, nonhuman hominoids, Neandertal lineage hominins and australopithecines), the threshold value obtained for significance is 0.0127 . Using the 0.0127 threshold would not change our results with one exception - the difference between Neandertal lineage hominins and australopithecines $(p=0.016)$ becomes marginally nonsignificant (Table 4).

We found a positive correlation between Lumbar lordosis and PI in nonhuman hominoids and hominin group averages (Table 5 and Figure 5, $\mathrm{R}^{2}=0.962, p<0.001$ ) and in living human and non human hominoids individuals (Figure 6, $\mathrm{R}^{2}=$ $0.658, p<0.01)$.

\section{Discussion}

The transition from quadrupedal to bipedal gait appears to have involved, among other things, a change in sacral orientation as measured by PI, if the morphology of extant nonhuman hominoids is a good proxy of that of stem hominoids. All bipedal hominins studied here show greater PIs $\left(32^{\circ}-54^{\circ}\right)$ than nonhuman hominoids $\left(27^{\circ} \pm 5^{\circ}\right)$, but the difference does not reach significance for the Neandertal lineage hominins. The two australopithecines specimens are similar $\left(42^{\circ}\right.$ and $\left.45^{\circ}\right)$ as

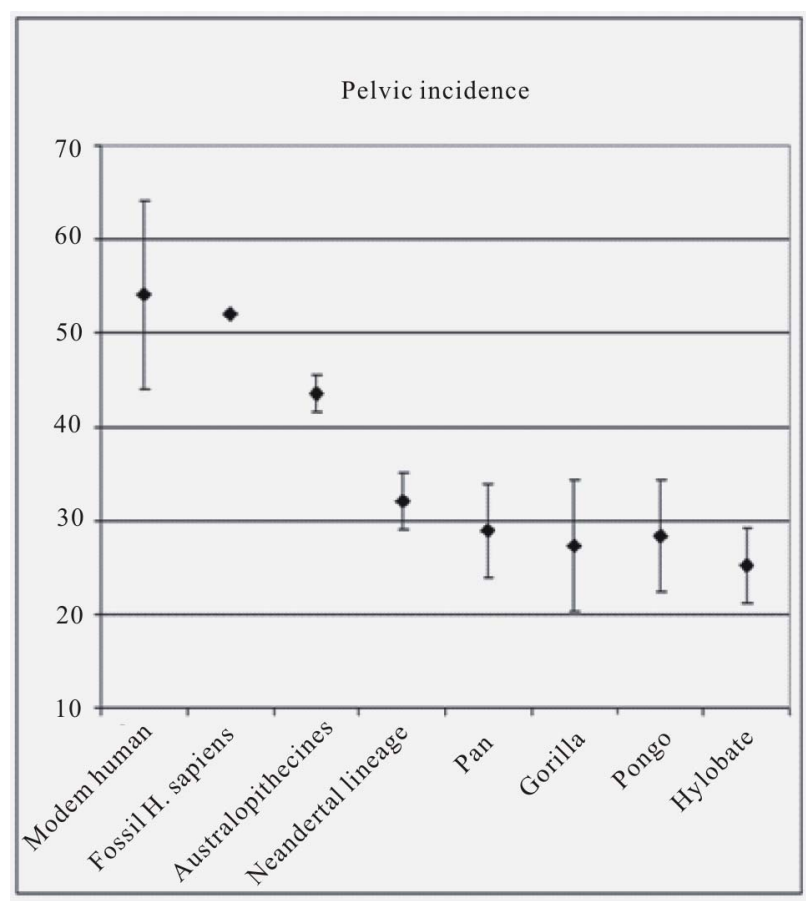

Figure 4.

Pelvic incidence of modern humans, fossil hominins and nonhuman hominoids. Diamond = average; $\mathrm{Bar}=$ one standard deviation. are the three Neandertal lineage hominins $\left(34^{\circ}, 28^{\circ}\right.$ and $\left.33^{\circ}\right)$, providing support for those groupings.

Our results from the modern human group are similar to previously published data (Table 3). The PIs of the australopithecines in our study $\left(42^{\circ}\right.$ for AL-288- 1 and $45^{\circ}$ for STS-14) are lower than those published by Tardieu et al. (2006) $\left(43^{\circ}-47^{\circ}\right.$ for AL-288-1, and $47^{\circ}-54^{\circ}$ for STS-14). While our results are based on the reconstructions by Robinson (1972) for STS-14 and Lovejoy (1979) for AL-288-1, Tardieu et al. (2006) measured the PI of these specimens using the reconstruction by Schmid (1983) for AL-288-1 and by Hausler (1992) for STS-14. Using the values by Tardieu et al. would make australopithecines more like modern humans, making more obvious the difference between all other hominins and the Neandertal lineage hominins. Our results regarding the orientation of the sacrum of australopithecines - smaller PI compared to H. sapiens - are in agreement with Berge and Gualaras (2010), but contradict the results of Abitbol (1995a, 1995b). Regarding the Neandertal lineage hominins our results support the findings of Weaver (2002) that has previously shown that the sacral tilt of Neanderthals is smaller in relation to the pelvis than in modern humans (corresponding to smaller PI).

\section{Evolutionary Perspective of PI}

When Neandertal lineage hominins are ignored, our results indicate a fairly simple path of evolution from quadrupedal apes to bipedal humans, with two stages in the development of PI during the course of hominin evolution. The early stage was characterized by an increase of about $15^{\circ}$ in PI, from $\sim 27^{\circ}$ in nonhuman hominoids to $\sim 43^{\circ}$ in australopithecines. This early stage probably happened concurrent with the appearance of bipedalism and lasted for several million years. The second increase in PI occurred later in human evolution, with an increase of about $10^{\circ}$ shown by $H$. sapiens. The timing of that second increase cannot be exactly determined from our data, because we were unable to measure the pelvis that is known of early genus Homo (the Gona pelvis). Based on the value of the lumbar lordosis of the H. erectus specimen KNM-WT 15,000 $\left(45^{\circ}\right)$ and the high correlation between the lordosis angle and PI, we can speculate that its PI was similar to that of australopithecines (between $40^{\circ}-45^{\circ}$ ). If this holds true for other early Homo specimens it would imply that the second increase happened later in human evolution as we find this second increase of $10^{\circ}$ only in the pelves of $H$. sapiens.

The small PI of the Neandertal lineage hominins (only $5^{\circ}$ higher than that of nonhuman hominoids) complicates the scenario. The difference in PIs between the Neandertal lineage hominins and australopithecines is only marginally significant $(p=0.016)$. Although we require additional information in order to decide whether or not the difference between the two groups in PI is significant, the pattern among hominin groups for PI is similar to that shown by lumbar lordosis (Been et al., 2012). This pattern suggests that the small PI angles of Neandertal lineage hominins (similar to the small lordotic angle, see Table 5) represents a reversal in the morphological trend of increasing PIs along hominin evolution.

\section{Functional Perspective of PI}

The emergence of bipedal walking probably happened before 4.4 MYA, as can be seen by the pelvis, femur, and preserved thoracic elements of Ardipithecus ramidus (Lovejoy et al., 
Table 3.

Pelvic incidence of modern humans.

\begin{tabular}{ccccc}
\hline Method & PI & Age & N & Research \\
\hline Radiographs & $52 \pm 5$ & Adult $26 \pm 6$ & 160 & Labelle et al. 2004 \\
Radiographs & $56 \pm 10$ & Adult $20-70$ & 300 & Vialle et al., 2005 \\
Radiographs & $53 \pm 9$ & Adult $19-50$ & 149 & Boulay et al., 2006 \\
& $54 \pm 12$ & Adult & 424 & Peleg et al., 2007 \\
3D & $52 \pm 12$ & $21-40$ & 169 & 157 \\
Radiographs & $55 \pm 13$ & $61-60$ & 98 & Legaye \& Duval-Beaupère. 2008 \\
Radiographs +3D & $55 \pm 13$ & Adult & Current study \\
\hline
\end{tabular}

Table 4.

Individual comparison of the pelvic incidence between the fossil individuals and the modern human and nonhuman hominoids sample using Z-scores and Mann-Whitney's U-test.

\begin{tabular}{|c|c|c|c|c|c|c|}
\hline \multirow[b]{2}{*}{ Sample } & \multirow[b]{2}{*}{ Individual } & \multirow[b]{2}{*}{ Pelvic incidence } & \multicolumn{2}{|c|}{ Z-score } & \multicolumn{2}{|c|}{ Mann-Whitney } \\
\hline & & & $\begin{array}{l}\text { Modern } \\
\text { human }\end{array}$ & $\begin{array}{l}\text { Nonhuman } \\
\text { hominoids }\end{array}$ & $\begin{array}{l}\text { Modern } \\
\text { human }\end{array}$ & $\begin{array}{l}\text { Nonhuman } \\
\text { hominoids }\end{array}$ \\
\hline Fossil H. sapiens & Ohalo & 52 & -0.2 & $5^{* *}$ & & \\
\hline H. neanderthalensis & Kebara 2 & 34 & $-2^{*}$ & 1.4 & & \\
\hline H. heidelbergensis & Sima de los Huesos, pelvis 1 & 28 & $-2.6^{* *}$ & 0.2 & & \\
\hline H. heidelbergensis & Sima de los Huesos, pelvis 2 & 33 & $-2.1^{*}$ & 1.2 & & \\
\hline Neandertal lineage & Sample mean \pm SD & $31.7 \pm 3.2$ & & & $0.0002^{* * *}$ & 0.114 \\
\hline Australopithecus africanus & STS - 14 & 45 & -0.9 & $3.6^{* *}$ & & \\
\hline Australopithecus afarensis & AL 288-1 & 42 & -1.2 & $3^{* *}$ & & \\
\hline Australopithecus & Sample mean \pm SD & $43.5 \pm 2$ & & & $0.0097^{* * *}$ & $0.0078^{* * *}$ \\
\hline$\underset{\text { (range) }}{\text { Modern human mean }} \pm \mathrm{SD}$ & & $\begin{array}{c}54 \pm 10 \\
(32-84)\end{array}$ & & & & \\
\hline $\begin{array}{c}\text { Nonhuman hominoids mean } \\
\pm \mathrm{SD} \text { (range) }\end{array}$ & & $\begin{array}{c}27 \pm 5 \\
(20-38) \\
\end{array}$ & & & & \\
\hline
\end{tabular}

Note: ${ }^{*} \mathrm{p}<0.05 ;{ }^{* *} \mathrm{p}<0.01$. If we apply the Dunn-Šidák correction for multiple comparisons $\left[1-(1-\alpha)^{1 / n}\right]$ with an $\alpha=0.05$ and four groups considered (modern humans, nonhuman hominoids, neandertal lineage and australopiths) the threshold value obtained for significance 0.0127 , and there will be no change in our results.

Table 5.

Pelvic incidence (PI) and lumbar lordosis angle (LA) of modern humans, fossil hominins and nonhuman hominoids.

\begin{tabular}{ccc}
\hline & PI & LA* \\
& $\mathrm{Xd}$ (range) & $\mathrm{X} \pm \mathrm{sd}$, (range) \\
\hline Nonhuman hominoids (total) & $27 \pm 5(20-38)$ & $22 \pm 3.4(18-28)$ \\
Pan & $29 \pm 6$ & 21 \\
Gorilla & $28 \pm 7$ & 25 \\
Pongo & $28 \pm 6$ & 19 \\
Hylobates & $25 \pm 4$ & 22 \\
Modern H. sapiens & $54 \pm 10(32-84)$ & $51 \pm 11(24-75)$ \\
Fossil H. sapiens & 52 & $54 \pm 14(44-64)$ \\
Neandertal & 34 & $29 \pm 4(25-32)$ \\
Australopithecines & $43.5 \pm 2$ & $41 \pm 4(38-44)$ \\
\hline
\end{tabular}

*After Been et al. 2012.

2009), and despite the retention of a capacity for substantial arboreal locomotion. The pelvis and femur of australopithecines indicate habitual bipedality in these hominins (Lovejoy, 2005; Ward, 2002; Crompton et al., 2008), and later hominins from the genus Homo are all considered to be habitual bipedal walkers (Aiello \& Wells, 2002; Crompton et al., 2008). Increased sacral tilt (more angled sacrum in relation to the iliac blades and greater PI) helps to bring the weight of the upper body closer to the acetabulum, and it enlarges the pelvic midplane and outlet to accommodate a large fetal head (Tague \& Lovejoy, 1986; Ward, 2002).

The difference in PI angles among the bipedal hominins (from $32^{\circ}$ in Neandertal lineage hominins to $54^{\circ}$ in H. sapiens) infers postural, locomotor and/or obstetrical differences between the groups. All premodern hominins - australopithecines as well as archaic Homo - apparently had mediolaterally very wide pelves, related to an M-L widened birth canal and a possible non-rotational birth mechanism (Ruff, 2010). Our results show that hominins with wide pelves (australopithecines and Neandertal lineage hominins) have smaller PI angles (more vertical sacra) than do hominins with narrow pelves (fossil and modern H. sapiens). If all else is the same, decreased PI angle 

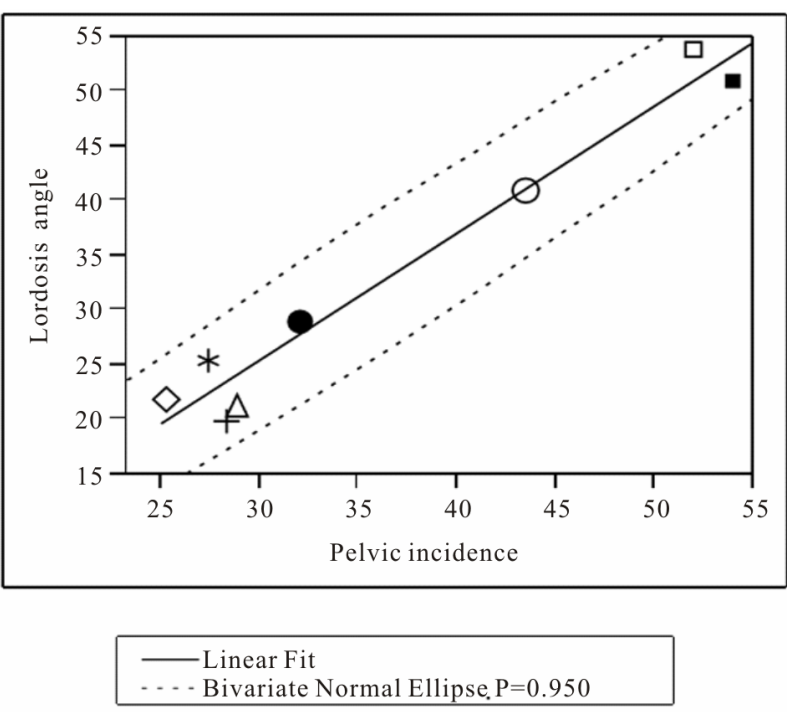

Linear Fit

Lordosis angle $=-9.182217+1.1580588^{*}$ Pelvic incidence

Figure 5.

Bivariate Fit of Lordosis angle (average) by Pelvic incidence (average) in modern humans, fossil hominins and nonhuman hominoids. $\mathrm{R}^{2}=$ $0.962, p<0.01$. - = Modern humans; $\square=$ Fossil H. sapiens; $\bullet=$ Neandertal lineage hominins; $\circ=$ Australopithecine; $\Delta=$ Pan; $*$ = Gorilla $;+$ $=$ Pongo $; \diamond=$ Hylobates .

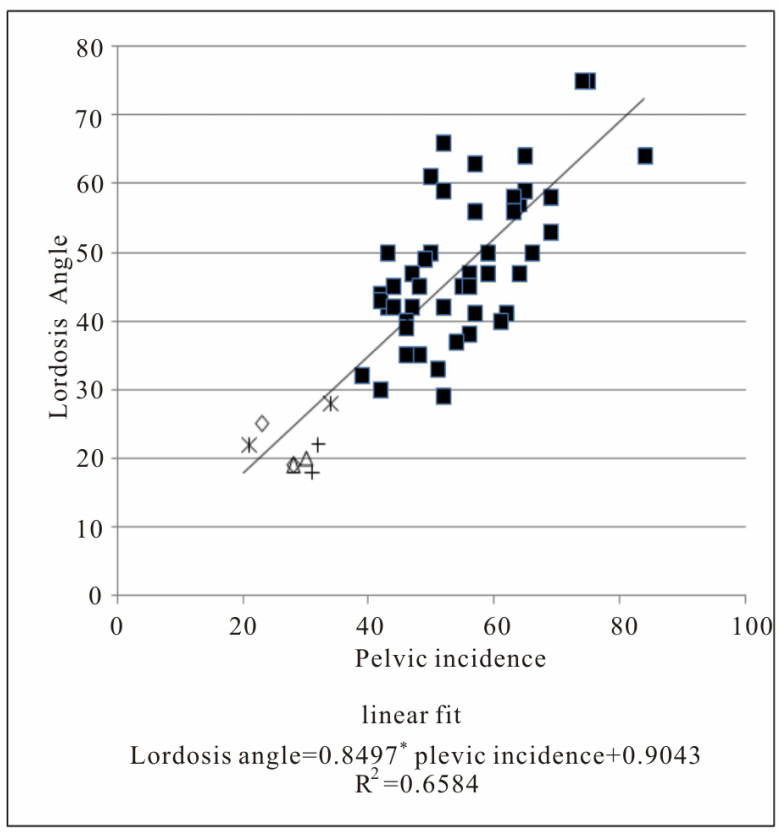

\section{Figure 6.}

Bivariate Fit of Lordosis angle by Pelvic incidence in modern humans and nonhuman hominoids living individuals. $\mathrm{R}^{2}=0.658, p<$ 0.01. $=$ Modern humans; $\Delta=$ Pan $; *=$ Gorilla $;+=$ Pongo; $\diamond=$ Hylobates.

(a more vertical sacrum) locates the sacral tip $\left(\mathrm{S}_{5}\right)$ closer to the pubis and the ischial tuberosities and, therefore, might decrease the anteroposterior dimension of the pelvic midplane and outlet (Hogervorst et al., 2009; See Figure 7).

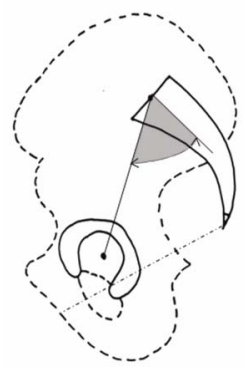

(a)

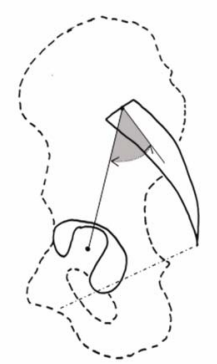

(b)

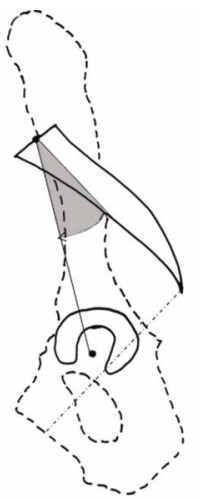

(c)
Figure 7.

Schematic illustration of PI and pelvic outlet of nonhuman hominoids, australopithecines and modern humans. (a) Modern human; (b) Australopithecines; (c) Nonhuman hominoid. Shaded gray area = pelvic incidence; $-\cdot \cdot \cdot \cdot=$ pelvic outlet.

\section{PI and the Lordotic Curvature}

We found a close correlation between PI and lumbar lordosis in hominins and nonhuman hominoids $\left(\mathrm{R}^{2}=0.962\right.$ for group averages, and $\mathrm{R}^{2}=0.658$ for living individuals). This finding expands the already established correlation between PI and lumbar lordosis in modern humans (Vaz et al., 2002; Boulay et al., 2006; Lee, 2010). The correlation implies that PI is a good indicator of the lumbar lordosis of hominoid specimens.

In conclusion, despite diversity in the sample composition (skeletal, casts, radiology, different reconstruction processes, pathological individuals) and small sample sizes (of the fossil hominins and apes), a pattern of change in pelvic incidence during the course of human evolution emerges from the present study. This change probably happened in response to the particular biomechanical and obstetrical demands that bipedalism exerted on each hominin species. H. sapiens has a narrow pelvis and higher PIs (more horizontal sacrum in relation to the iliac blades); australopithecines and Neandertal lineage hominins have a wider pelvis and smaller PIs. The correlation between PIs and lumbar lordosis angles in hominins and nonhuman hominoids can be used to estimate the lordosis angles in hominoid subgroups where only the pelvis is intact.

\section{Acknowledgements}

The authors wish to thank Dr. Itzhak Aizenberg, Koret School of Veterinary Medicine, Hebrew University, Jerusalem; Dr. Nili Avni-Magen, Biblical Zoo, Jerusalem; Ms. Zila Shariv, Zoology Museum, Tel Aviv University; And Dr. Yigal Horovits, Saphari, Ramat-Gan, for enabling us to study radiographs and skeletal material in their care. Special thanks to Prof. Yoel Rak, Dr. Michal Katz, Avishag Ginzburg, and Alon Barash for their useful comments.

\section{REFERENCES}

Abitbol, M. M. (1987). Evolution of the lumbosacral angle. American Journal of Physical Anthropology, 72, 361-372. doi:10.1002/ajpa.1330720309

Abitbol, M. M. (1995a). Reconstruction of the STS-14 (Australopithecus africanus) pelvis. Journal of Physical Anthropology, 96, $143-$ 
158. doi:10.1002/ajpa.1330960204

Abitbol, M. M. (1995b). Lateral view of Australopithecus afarensis: Primitive aspects of bipedal positional behavior in earliest hominids. Journal of Human Evolution, 28, 211-229. doi:10.1002/ajpa.1330960204

Aiello, L. C., \& Wells, J. C. K. (2002). Annual review of anthropology. Energetics and the evolution of the genus homo. Annual Review of Anthropology, 31, 323-338. doi:10.1146/annurev.anthro.31.040402.085403

Arensburg, B., Bar-Yosef, O., Chech, M., Goldberg, P., Laville, H., Meignen, L., Rak, Y., Tchernov, E., Tillier, A.-M., \& Vandermeersch, B. (1985). Une se' pulture ne'andertalienne dans la grotte de Kebara (Israel). Comptes Rendus de l'Académie des Sciences, 300, 227-230.

Been, E., Barash, A., Marom, A., Aizenberg, I., \& Kramer, P. (2010). A new model for calculating the lumbar lordosis angle in early hominids and in the spine of the neandertal from Kebara. The Anatomical Record, 293, 1140-1145. doi:10.1002/ar.21145

Been, E., Pessah, H., Been, L., Tawil, A., \& Peleg, S. (2007). New method for predicting the lumbar lordosis angle in skeletal material. The Anatomical Record, 290, 1568-1573. doi:10.1002/ar.20607

Been, E., Gómez-Olivencia, A., \& Kramer, P. A. (2012). Lumbar lordosis of extinct hominins. American Journal of Physical Anthropology, 147, 64-77. doi:10.1002/ajpa.21633

Berge, C., \& Gualaras, D. (2010). A new reconstruction of STS-14 pelvis (Australopithecus africanus) from computed tomography and three-dimensional modeling techniques. Journal of Human Evolution, 58, 262-272. doi:10.1016/j.jhevol.2009.11.006

Bischoff, J. L., Williams, R. W., Rosenbauer, R. J., Aramburu, A., Arsuaga, J. L., García, N., \& Cuenca-Bescós, G. (2007). High-resolution U-series dates from the Sima de los Huesos hominids yields $600_{-66}^{+\infty}$ kyrs: Implications for the evolution of the early Neanderthal lineage. Journal of Archaeological Science, 34, 763-770. doi:10.1016/j.jas.2006.08.003

Bonmatí, A., Gómez-Olivencia, A., Arsuaga, J. L., Carretero, J. M., Gracia, A., Martínez, I., Lorenzo, C., Bermúdez de Castro, J. M., \& Carbonell, E. (2010). A middle pleistocene lower back and pelvis from an aged individual from the Sima de los Huesos site, Spain. Proceedings of the National Academy of Sciences, 107, 1838618391. doi:10.1073/pnas.1012131107

Bonmatí, A., Arsuaga, J. L., \& Lorenzo, C. (2008). Revisiting the developmental stage and age-at-death of the "Mrs. Ples" (STS-5) and STS-14 specimens from Sterkfontein (South Africa): Do they belong to the same individual? The Anatomical Record, 291, 1707-1722. doi: $10.1002 / \mathrm{ar} .20795$

Boulay, C., Tardieu, C., Hecquet, J., Benaim, C., Mitulescu, A., Marty, C., Prat-Pradal, D., Legaye, J., Duval-Beaupère, G., \& Pélisser, J. (2005). Anatomical reliability of two fundamental radiological and clinical pelvic parameters: Incidence and thickness. European Journal of Orthopaedic Surgery \& Traumatology, 15, 197-204. doi:10.1007/s00590-005-0239-5

Boulay, C., Tardieu, C., Hecquet, J., Benaim, C., Mouilleseaux, B., Marty, C., Prat-Pradal ,D., Legaye, J., Duval-Beaupère, G., \& Pélissier, J. (2006). Sagittal alignment of spine and pelvis regulated by pelvic incidence: Standard values and prediction of lordosis. European Spine Journal, 15, 415-422. doi:10.1007/s00586-005-0984-5

Crompton, R. H., Vereecke, E. E., \& Thorpe, S. K. S. (2008). Locomotion and posture from the common hominoid ancestor to fully modern hominins, with special reference to the last common panin/ hominin ancestor. Journal of Anatomy, 212, 501-543. doi:10.1111/j.1469-7580.2008.00870.x

Duday, H., \& Arensburg, B. (1991). La Pathologie. In O. Bar-Yosef, \& B. Vandermeersch (Eds.), Le squelette moustérien de kébara 2 (pp. 179-194). Paris: Centre National de la Recherche Scientifique.

During, J, Goudfrooij, H., Keessen, W., Beeker, W., \& Crowe, A. (1985). Toward standards for posture. Postural characteristics of the lower back system in normal and pathological conditions. Spine, 10, 83-87. doi:10.1097/00007632-198501000-00013

Duval-Beaupère, G., Schmidt, C., \& Cosson, P. (1992). A barycentremetric study of the sagittal shape of spine and pelvis: The condition required for an economic standing position. Annals of Biomedical Engineering, 20, 451-462. doi:10.1007/BF02368136

Ferguson, A. B. (1934). The clinical and roentgenographic interpretation of lumbosacral anomalies. Radiology, 22, 548-558.

Gardocki, R. J., Watkins, R. G., \& Williams, L. A. (2002). Measurements of lumbopelvic lordosis using the pelvic radius technique as it correlates with sagittal spinal balance and sacral translation. The Spine Journal, 2, 421-429. doi:10.1016/S1529-9430(02)00426-6

Hausler, M. (1992). Rekonstruktion des Beckens von STS-14 (Australopithecus africanus). Ph.D. Thesis, Zurich: Anthropologisches Institut und Museum der Universitat Zurich-Irchel.

Hogervorst, T., Bouma, H. W., \& de Vos, J. (2009). Evolution of the hip and pelvis. Acta Orthopaedica, 80, 1-39. doi:10.1080/17453690610046620

Jackson, R. P., \& McManus, A. C. (1994). Radiographic analysis of sagittal plane alignment and balance in standing volunteers and patients with low back pain matched for age, sex, and size. Spine, 19, 1611-1618. doi:10.1097/00007632-199407001-00010

Kibii, J. M., Churchill, S. E., Schmid, P., Carlson, K. J., Reed, N. D., De Ruiter, D. J., \& Berger, L. R. (2011). A partial pelvis of Australopithecus sediba. Science, 333, 1407-1411. doi:10.1126/science.1202521

Labelle, H., Roussouly, P., Berthonnaud, E., Dimnet, J., \& O’Brien, M. (2005). The importance of spino-pelvic balance in L5-S1 developmental spondylolisthesis. Spine, 30, S27-S34. doi:10.1097/01.brs.0000155560.92580.90

Labelle, H., Roussouly, P., Berthonnaud, E., Transfeldt, E., O’Brien, M., Chopin, D., Hresko, T., \& Dimne, J. (2004). Spondylolisthesis, pelvic incidence, and spinopelvic balance: A correlation study. Spine, 29, 2049-2054. doi:10.1097/01.brs.0000138279.53439.cc

Lazennec, J. Y., Charlot, N., Gorin, M., Roger, B., Arafati, N., Bissery, A., \& Saillant, G. (2004). Hip-spine relationship: A radio-anatomical study for optimization in acetabular cup positioning. Surgical and Radiologic Anatomy, 26, 136-144. doi:10.1007/s00276-003-0195-x

Lee, J. H., Kim, K. T., Suk, K. S., Lee, S. H., Jeong, B. O., Kim, J. S., Eoh, J. H., \& Kim, Y. J. (2010). Analysis of spinopelvic parameters in lumbar degenerative kyphosis: Correlation with spinal stenosis and spondylolisthesis. Spine, 35, E1386-1391. doi:10.1097/BRS.0b013e3181e88be6

Legaye, J. (2007). The femoro-sacral posterior angle: An anatomical sagittal pelvic parameter usable with dome-shaped sacrum. European Spine Journal, 16, 219-225. doi:10.1007/s00586-006-0090-3

Legaye, J., Duval-Beaupère, G., Hecquet, J., \& Marty, C. (1998). Pelvic incidence: A fundamental pelvic parameter for three-dimensional regulation of spinal sagittal curves. European Spine Journal, 7, 99103. doi: $10.1007 / \mathrm{s} 005860050038$

Legaye, J., \& Duval-Beaupère, G. (2008). Gravitational forces and sagittal shape of the spine. Clinical estimation of their relations. International Orthopaedics, 32, 809-816. doi:10.1007/s00264-007-0421-y

Lovejoy, C. O. (1979). A reconstruction of the pelvis of AL-288-1 (Hadar Formation, Ethiopia). American Journal of Physical Anthropology, 50, 413.

Lovejoy, C. O. (2005). The natural history of human gait and posture in Part 1. Spine and Pelvis, Gait and Posture, 21, 95-112.

Lovejoy, C. O., Suwa, G., Spurlock, L., Asfaw, B., \& White, T. D. (2009). The pelvis and femur of Ardipithecus ramidus: The emergence of upright walking. Science, 326, 71e1-71e6.

Nadel, D., \& Hershkovitz, I. (1991). New subsistence data and human remains from the earliest Levantine Epipaleolithic. Current Anthropology, 32, 631-635. doi:10.1086/204012

Peleg, S., Dar, G., Steinberg, N., Peled, N., Hershkovitz, I., \& Masharawi, Y. (2007). Orientation of the human sacrum: Anthropological perspectives and methodological approaches. American Journal of Physical Anthropology, 133, 967-977. doi:10.1002/ajpa.20599

Pérez, P. J. (2003). Recopilación de diagnósticos paleopatológicos en fósiles humanos, con casos relativos a homínidos de Atapuerca. In A. Isidro, \& A. Malgosa (Eds.), Paleopatología. La enfermedad no escrita (pp. 295-306). Barcelona: Masson. 
Rak, Y. (1991). The pelvis. In O. Bar-Yosef, \& B. Vandermeersch (Eds.), Le squelette Moustérien de Kébara 2 (pp. 113-146). Paris: Centre National de la Recherche Scientifique.

Robinson, J. T. (1972). Early hominid posture and locomotion. Chicago, IL: University of Chicago Press.

Ruff, C. B. (2010). Body size and body shape in early hominins -Implications of the Gona pelvis. Journal of Human Evolution, 58, 166-178. doi:10.1016/j.jhevol.2009.10.003

Schmid, P. (1983). Eine rekonstruktion des skelettes von AL-288-1 (Hadar) und deren konsequenzen. Folia Primatologica, 40, 283-306. doi:10.1159/000156111

Schwarcz, H. P., Grun, R., \& Tobias, P. V. (1994). Esr dating studies of the australopithecine site of Sterkfontein, South-Africa. Journal of Human Evolution, 26, 175-181. doi:10.1006/jhev.1994.1010

Simpson, S. W., Quade, J., Levin, N. E., Butler, R., Dupont-Nivet, G., Everett, M., \& Semaw, S. (2008). A female homo erectus pelvis from Gona, Ethiopia. Science, 322, 1089-1092. doi:10.1126/science. 1163592

Stagnara, P., De Mauroy, J. C., Dran, G., Gonon, G. P., Costanzo, G., Dimnet, J., \& Pasquet, A. (1982). Reciprocal angulation of vertebral bodies in a sagittal plane. Approach to references for evaluation of kyphosis and scoliosis. Spine, 7, 335-342. doi:10.1097/00007632-198207000-00003

Stringer, C. (2012). The status of Homo heidelbergensis (Schoetensack 1908). Evolutionary Anthropology, 21, 101-107. doi:10.1002/evan.21311

Tague, R. G. (2000). Do big females have big pelves? American Journal of Physical Anthropology, 112, 377-393. doi:10.1002/1096-8644(200007)112:3<377::AID-AJPA8>3.0.CO;2$\underline{\mathrm{O}}$

Tague, R. G., \& Lovejoy, C. O. (1986). The obstetric pelvis of AL288-1 (Lucy). Journal of Human Evolution, 15, 237-255. doi:10.1016/S0047-2484(86)80052-5
Tardieu, C., Hecquet, J., Boulay, C., Legaye, J., Marty, C., \& DuvalBeaupère, G. (2006). Le bassin, interface articulaire entre rachis et membres inférieurs: Analyse par le logiciel DE-VISU. Comptes Rendus Palevol, 5, 583-595. doi:10.1016/j.crpv.2005.12.015

Valladas, H., Joron, J. L., Valladas, G., Arensburg, B., Bar-Yosef, O., Belfer-Cohen, A., Goldberg, P., Laville, H., Meignen, L., Rak, Y., Tchernov, E., Tillier, A. M., \& Vandermeersch, B. (1987). Thermoluminescence dates for the Neanderthal burial site at Kebara in Israel. Nature, 330, 159-160. doi:10.1038/330159a0

,Vaz, G., Roussouly, P., Berthonnaud, E., \& Dimnet, J. (2002). Sagittal morphology and equilibrium of pelvis and spine. European Spine Journal, 11, 80-87.

doi: $10.1007 / \mathrm{s} 005860000224$

Vialle, R., Levassor, N., Rillardon, L., Templier, A., Skalli, W., \& Guigui, P. (2005). Radiographic analysis of the sagittal alignment and balance of the spine in asymptomatic subjects. The Journal of Bone \& Joint Surgery, 87, 260-267. doi:10.2106/JBJS.D.02043

Von Lackum, H. L. (1924). The lumbosacral region. The Journal of the American Medical Association, 82, 1109-1114. doi:10.1001/jama.1924.02650400019007

Walter, R. (1994). Age of Lucy and the first family: Single-crystal 40Ar/39Ar dating of the Denen Dora and lower Kada Hadar members of the Hadar formation, Ethiopia. Geology, 22, 6-10. doi:10.1130/0091-7613(1994)022<0006:AOLATF >2.3.CO;2

Ward, C. V. (1993). Torso morphology and locomotion in Proconsul nyanzae. American Journal of Physical Anthropology, 92, 291-328. doi:10.1002/ajpa.1330920306

Ward, C. V. (2002). Interpreting the posture and locomotion of Australopithecus afarensis: Where do we stand? Yearbook of Physical Anthropology, 45, 185-215. doi:10.1002/ajpa.10185

Weaver, T. D. (2002). A multi-causal functional analysis of hominid hip morphology. Ph.D. Thesis, Stanford: Stanford University. 